\title{
ARTICLE Diabetes downregulates peptide transporter 1 in the rat jejunum: possible involvement of cholate-induced FXR activation
}

\author{
Li-min Liang ${ }^{1}$, Jun-jie Zhou ${ }^{1}$, Feng $\mathrm{Xu}^{1}$, Pei-hua Liu ${ }^{1}$, Lan Qin ${ }^{1}$, Li Liu ${ }^{1}$ and Xiao-dong Liu ${ }^{1}$
}

Peptide transporter 1 (PepT1), highly expressed on the apical membrane of enterocytes, is involved in energy balance and mediates intestinal absorption of peptidomimetic drugs. In this study, we investigated whether and how diabetes affected the function and expression of intestinal PepT1. Diabetes was induced in rats by combination of high-fat diet and low dose streptozocin injection. Pharmacokinetics study demonstrated that diabetes significantly decreased plasma exposures of cephalexin and acyclovir following oral administration of cephalexin and valacyclovir, respectively. Single-pass intestinal perfusion analysis showed that diabetes remarkably decreased cephalexin absorption, which was associated with decreased expression of intestinal PepT1 protein. We assessed the levels of bile acids in intestine of diabetic rats, and found that diabetic rats exhibited significantly higher levels of chenodeoxycholic acid (CDCA), cholic acid (CA) and glycocholic acid (GCA), and lower levels of lithocholic acid (LCA) and hyodeoxycholic acid (HDCA) than control rats; intestinal deoxycholic acid (DCA) levels were unaltered. In Caco-2 cells, the 6 bile acids remarkably decreased expression of PepT1 protein with CDCA causing the strongest inhibition, whereas TNF-a, LPS and insulin little affected expression of PepT1 protein; short-chain fatty acids induced rather than decreased expression of PepT1 protein. Farnesoid X receptor (FXR) inhibitor glycine- $\beta$-muricholic acid or FXR knockdown reversed the downregulation of PepT1 expression by CDCA and GW4064 (another FXR agonist). In diabetic rats, the expression of intestinal FXR protein was markedly increased. Oral administration of CDCA $\left(90,180 \mathrm{mg} \cdot \mathrm{kg}^{-1} \cdot \mathrm{d}^{-1}\right.$, for 3 weeks) dose-dependently decreased the expression and function of intestinal PepT1 in rats. In conclusion, diabetes impairs the expression and function of intestinal PepT1 partly via CDCAmediated FXR activation.

Keywords: peptide transporter 1; diabetes; farnesoid X receptor; Caco-2 cells; intestine; chenodeoxycholic acid

Acta Pharmacologica Sinica (2020) 41:1465-1475; https://doi.org/10.1038/s41401-020-0408-4

\section{INTRODUCTION}

Diabetes, a metabolic disease, is often accompanied by multifarious complications such as infection and hypertension. Peptidomimetic drugs, including $\beta$-lactam antibiotics (such as cephalexin, cefadroxil and ceftibuten) [1-4], antivirals (such as oseltamivir and valacyclovir) [5-9], angiotensin-converting enzyme inhibitors (such as quinapril, lisinopril, benazepril, and enalapril) [10, 11], bestatin and other therapeutically active molecules, may be applied to treat complications of diabetes. Most peptidomimetic drugs are substrates of peptide transporter 1 (PepT1). The intestinal PepT1, a proton-coupled oligopeptide transporter encoded by SLC15A1, is abundantly localized on the apical membrane of enterocytes from the duodenum to ileum and uses the proton $\left(\mathrm{H}^{+}\right)$gradient across the membrane to cotransport its substrates, inferring a pivotal role of PepT1 in intestinal absorption of these peptidomimetic drugs. PepT1 is also implicated in energy balance. PepT1 transports almost all dipeptides and tripeptides resulting from dietary breakdown of proteins [12] and is responsible for the absorption of $70 \%$ of the dietary nitrogen supplied to the body [13]. PepT1 $1^{-1-}$ mice showed markedly lower weight gain and body fat stores and higher fecal energy losses than wild-type mice when they were fed high-fat or high-protein diets $[12,13]$. PepT1 also mediates the transport of bacterial peptidomimetics (such as muramyl dipeptide, $\mathrm{N}$-formylmethionyl-leucyl-phenylalanine, $L$-alanyl- $\gamma$ - $D$-glutamyl-meso-diaminopimelic acid and $\gamma$ - $D$-glutamyl-meso-diaminopimelic acid), which regulates intestinal inflammatory responses by mediating the transport of these chemotactic peptides across intestinal epithelial cells [14]. Moreover, proton-coupled electrogenic dipeptide uptake via PepT1 also contributes significantly to intestinal fluid transport [15]. The small intestinal protein-sensing mechanisms mediated by PepT1 have beneficial effects on wholebody glucose homeostasis [16, 17].

Animal experiments have demonstrated that a high-fat diet [18] and diabetes [18-20] remarkably decreased the expression of intestinal PepT1, leading to a decrease in the influx rate of the PepT1 substrate glycylsarcosine across the intestinal wall $[19,20]$, although a contradictory report was also found [21]. Similarly, mice fed high-fat diets and diabetic mice also exhibited reduced expression of intestinal PepT1 [22-24]. These findings may have relevance to the modulation of dietary nitrogen supply and PepT1 substrate bioavailability in obesity and diabetes. Several

${ }^{1}$ Center of Drug Metabolism and Pharmacokinetics, College of Pharmacy, China Pharmaceutical University, Nanjing 210009, China

Correspondence: Li Liu (liulee@yeah.net) or Xiao-dong Liu (xdliu@cpu.edu.cn)

Received: 14 January 2020 Accepted: 24 March 2020

Published online: 27 April 2020 
reports have shown that diabetes-induced decreases in the expression and function of intestinal PepT1 may be reversed by insulin treatment $[19,20]$. In Caco-2 cells, leptin and insulin increased the transport of the PepT1 substrates cephalexin and glycylsarcosine, which was associated with increased membrane PepT1 protein $[3,24,25]$. Ob/ob mice (leptin ${ }^{-1-}$ mice) showed reduced expression and function of intestinal PepT1, which was reversed by leptin treatment. Leptin treatment also increased the expression and activity of intestinal PepT1 in rats [25]. All these results indicate that leptin deficiency and insulin deficiency may explain the downregulation of the expression and function of intestinal PepT1. Importantly, diabetes and obesity also remarkably alter the intestinal environment, such as increased levels of shortchain fatty acids (SCFAs) [18] and dyshomeostasis of bile acid composition [26-29]. Our preliminary data demonstrated that the expression of PepT1 protein in Caco-2 cells was downregulated by several bile acids, such as glycocholic acid (GCA), cholic acid (CA), lithocholic acid (LCA), chenodeoxycholic acid (CDCA), deoxycholic acid (DCA) and hyodeoxycholic acid (HDCA), among which, CDCA showed the strongest inhibitory effect. These results suggest that abnormal alterations in bile acid compositions induced by diabetes may impair the expression and function of intestinal PepT1. Bile acids, natural ligands of the farnesoid $X$ receptor (FXR), often show their biological effect by activating FXR [30].

The aims of the study were to (1) further investigate whether diabetes downregulated the expression and function of intestinal PepT1 in diabetic rats and the possible mechanism-two PepT1 substrates, cephalexin and valacyclovir, were selected to document the function of intestinal PepT1 in rats; (2) explore whether bile acids, especially CDCA, impaired the expression of intestinal PepT1 and whether the downregulation of PepT1 by CDCA was implicated in the activation of FXR using both an FXR antagonist and FXR knockdown with FXR siRNA in Caco-2 cells; and (3) further confirm the role of CDCA in the protein expression and function of intestinal PepT1 in CDCA-treated rats. The results would aid in understanding the clinical significance of alterations in the expression and function of intestinal Pept1 under diabetic conditions.

\section{MATERIALS AND METHODS}

Chemicals and materials

Valacyclovir, acyclovir, heparin, lithocholic acid (LCA), cholic acid (CA), hyodeoxycholic acid (HDCA) and butyrate were obtained from Aladdin (Shanghai, China). Cephalexin was purchased from Ark Pharminc (Arlington Heights, IL, USA). Streptozotocin (STZ) and lipopolysaccharide (LPS) were purchased from Sigma-Aldrich (St. Louis, MO, USA). Chenodeoxycholic acid (CDCA) was purchased from Macklin Biochemical (Shanghai, China). Deoxycholic acid (DCA) was from Adamas-beta (Shanghai, China), and glycocholic acid (GCA) was from Meilun Biological Technology (Dalian, China). GW4064 was purchased from Selleck Chemicals (Shanghai, China). Glycine- $\beta$-muricholic acid (MCA) was purchased from Zixia Biotechnology (Shanghai, China). Tumor necrosis factora (TNF-a) was purchased from ScienCell (San Diego, CA, USA). Acetate and propionate were from Energy Chemical (Shanghai, China). The BCA kit, RIPA lysis buffer and loading buffer were from Beyotime Biotechnology (Nanjing, China). Activity assay kits for triglyceride, total cholesterol and glucose were from Jiancheng Bioengineering Institute (Nanjing, China). The monoclonal antibody for PepT1 was from Santa Cruz Biotechnology (Dallas, TX, USA), the monoclonal antibody for FXR was from Merck (Kenilworth, NJ, USA), and the antibody for $\beta$-actin was from Bioworld Technology (Bloomington, MN, USA). All other chemicals were commercially available.

Animals

Male Sprague-Dawley rats weighing $100-120 \mathrm{~g}$ were obtained from Super-B\&K Laboratory Animal Co. (Shanghai, China). Rats were kept in an air-conditioned $\left(24 \pm 2{ }^{\circ} \mathrm{C}\right)$ room with a controlled $12 \mathrm{~h} / 12 \mathrm{~h}$ light-dark cycle and relative humidity $(50 \% \pm 5 \%)$. Rats were maintained on regular or high-fat chow with drinking water available ad libitum. The animal studies were performed in accordance with the Guide for the Care and Use of Laboratory Animals (National Institutes of Health) and approved by the China Pharmaceutical University Animal Ethics Committee (No. 20180006002928).

\section{Development of diabetic rats}

Diabetic rats were induced according to a previous protocol [18]. In brief, rats were assigned randomly to three groups: diabetic (DM) rats, high-fat diet (HFD) rats and control (CON) rats. The CON rats received regular chow, while both DM rats and HFD rats received a high-fat diet consisting of $13 \%$ lard, $2 \%$ sesame oil, $20 \%$ sucrose, $3 \%$ cholesterol, $5 \%$ peanut, $0.1 \%$ sodium cholate and $57 \%$ normal chow (TROPHIC Animal Feed Co., Ltd, Nantong, China). Following 6 weeks of feeding with a high-fat diet, DM rats were intraperitoneally (ip) administered STZ $(35 \mathrm{mg} / \mathrm{kg}$, in citratebuffered saline, $\mathrm{pH} 4.5$ ), and both HFD rats and CON rats received an equivalent volume of the vehicle. On the 7th day after STZ or vehicle injection, fasting blood glucose (FBG), fasting plasma insulin (FINS), total cholesterol (TC) and triglyceride (TG) were measured. Only rats with FBG levels higher than $11 \mathrm{mM}$ were considered diabetic rats [18] and used for the following studies.

Pharmacokinetics of cephalexin and valacyclovir after oral administration to experimental rats

On the 21st day after STZ or vehicle injection, the pharmacokinetics of cephalexin or valacyclovir in DM rats, HFD rats and CON rats following oral administration were investigated. In brief, the experimental rats were fasted overnight and orally administered cephalexin $(5 \mathrm{mg} / \mathrm{kg}$, dissolved in normal saline) or valacyclovir $(18.4 \mathrm{mg} / \mathrm{kg}$, dissolved in normal saline). The dosages of cephalexin and valacyclovir were designed based on previous reports $[4,7]$. Blood samples $(\sim 120 \mu \mathrm{L})$ were collected into heparinpretreated microcentrifuge tubes at designated times $(15,30,45$, $60,75,90,120,180,240$ and 480 min for cephalexin; 5, 15, 30, 45, $60,120,180,240$ and 360 min for valacyclovir) after administration via the oculi chorioideae vein under light ether anesthesia. After each 4 samplings, a suitable amount of normal saline was administered to the experimental rats via the tail vein to compensate for blood loss. Plasma samples were obtained by centrifugation. Plasma concentrations of acyclovir and cephalexin were measured using HPLC and LC-MS methods, respectively.

On the 22nd day after STZ or vehicle injection, the rats, fasted overnight, were sacrificed under diethyl ether anesthesia. Intestinal tissues were quickly obtained for determining the expression of target proteins. The small intestine contents were also collected in $2 \mathrm{~mL}$ of $0.9 \%$ saline for measuring levels of bile acids.

Intestinal absorption of cephalexin in the jejunum of rats The intestinal absorption of cephalexin in the jejunum was evaluated by in situ single-pass perfusion according to a previous protocol [31]. Briefly, the experimental rats, fasted overnight, were anesthetized with pentobarbital $(60 \mathrm{mg} / \mathrm{kg}$, ip). The upper jejunum segment $(10 \mathrm{~cm})$ was isolated, and two cannulas were inserted at either end of the isolated jejunum. The isolated intestinal segment was perfused with saline solution $\left(37^{\circ} \mathrm{C}\right)$ for $10 \mathrm{~min}$, followed by Krebs-Henseleit buffer containing cephalexin $(40 \mu \mathrm{M})$ at $0.2 \mathrm{~mL} /$ min for $15 \mathrm{~min}$ (reaching steady state). Then, consecutive effluent samples were collected every $15 \mathrm{~min}$ for $120 \mathrm{~min}$ via the distal cannula. The concentration of cephalexin was designed according to the preliminary data. At the end of perfusion, the rats were sacrificed, and the area of perfused intestinal segments $A\left(\mathrm{~cm}^{2}\right)$ was measured. The apparent effective permeability $\left(P_{\text {eff, }} \mathrm{cm} / \mathrm{min}\right)$ was estimated using the following equation, i.e., 
$P_{\text {eff }}=-Q \times \ln \left(C_{\text {out }} / C_{\text {in }}\right) / A$, where $C_{\text {in }}(\mu \mathrm{M})$ and $Q(\mathrm{~mL} / \mathrm{min})$ are the cephalexin concentration in the inflow and the flow rate, respectively. $C_{\text {out }}(\mu \mathrm{M})$ was the cephalexin concentration at the outflow and was corrected by the weight calibration method.

Cell culture and drug treatment

Human epithelial colorectal adenocarcinoma cells (Caco- 2 cells) were provided by the Cell Bank of the Chinese Academy of Science (Shanghai, China). Stable expression of PepT1 was demonstrated by western blot. Cells were cultured in highglucose Dulbecco's modified Eagle's medium containing 10\% fetal bovine serum (Gibco Thermo Fisher Inc., Waltham, MA, USA), penicillin $(100 \mathrm{IU} / \mathrm{mL}), L$-glutamine $(2 \mathrm{mM}), \mathrm{NaHCO}_{3}(3.7 \mathrm{mg} / \mathrm{mL})$ and nonessential amino acids and kept in a humidified incubator with $5 \% \mathrm{CO}_{2}$ and $95 \% \mathrm{O}_{2}$ at $37{ }^{\circ} \mathrm{C}$. Caco-2 cells were plated into 6 -well plates at a density of $2 \times 10^{5}$ cells/well. The medium was changed every 2 days. After incubation for 7 days, cells were incubated with culture medium containing CDCA $(100 \mu \mathrm{M})$, CA $(100 \mu \mathrm{M})$, DCA $(50 \mu \mathrm{M})$, HDCA $(100 \mu \mathrm{M})$, GCA $(100 \mu \mathrm{M})$, LCA $(12.5 \mu \mathrm{M})$ or vehicle for $48 \mathrm{~h}$. The concentrations of bile acids were designed according to preliminary experiments. Higher concentrations were not tested because of cytotoxicity or insolubility. Concentration-dependent effects of CDCA $(10 \mu \mathrm{M}, 50 \mu \mathrm{M}$ and $100 \mu \mathrm{M})$ on PepT1 levels were simultaneously measured. The effects of other factors, including LPS $(1 \mu \mathrm{g} / \mathrm{mL})$ [32], TNF- $a$ $(10 \mathrm{ng} / \mathrm{mL})$ [33], insulin $(5 \mathrm{nM})$ [34], SCFAs (acetate: propionate: butyrate $=10: 1: 1 \mathrm{mM}$ ) [18] and gemfibrozil (agonist of PPAR-a, $50 \mu \mathrm{M})$ [35] with or without CDCA $(100 \mu \mathrm{M})$, on the expression of PepT1 in Caco-2 cells were also documented. MTT assays demonstrated that these reagents caused no damage to Caco-2 cells at the tested concentrations.

Role of FXR activation in CDCA-regulated expression of PepT1 in Caco-2 cells

CDCA is considered a natural FXR agonist. MCA, an inhibitor of FXR [36], was used to investigate whether CDCA affected the expression of PepT1 by activating FXR. Caco- 2 cells were seeded in 6-well plates and exposed to CDCA $(100 \mu \mathrm{M})$ or GW4064 (another FXR agonist, $1 \mu \mathrm{M}$ ) [37] with or without MCA $(100 \mu \mathrm{M})$ for $48 \mathrm{~h}$. The role of FXR activation was further confirmed via FXR knockdown. FXR knockdown in Caco-2 cells was performed using FXR siRNA (NR1H4: 5'-GUGGUACUCUCCUGGAAUATT-3' and 5'UAUUCCAGGAGAGUACCACTT-3'), which was designed by GenePharma Technology (Shanghai, China), and Lipofectamine 3000 (Invitrogen, Carlsbad, CA, USA) according to the manufacturer's instructions. After $24 \mathrm{~h}$, the cells were incubated for another $48 \mathrm{~h}$ in culture medium containing CDCA $(100 \mu \mathrm{M})$ or GW4064 (1 $\mu \mathrm{M})$. The expression of PepT1 protein was measured.

Effects of CDCA on the expression and function of intestinal PepT1 in rats

Eighteen rats weighing $190-210 \mathrm{~g}$ were randomly divided into three groups $(n=6)$, i.e., rats treated with a low dose of CDCA (LCDCA), rats treated with a high dose of CDCA (H-CDCA) and control $(C O N)$ rats. $L-C D C A$ rats and $H-C D C A$ rats orally received CDCA $(90 \mathrm{mg} / \mathrm{kg}$, qd) and CDCA (180 mg/kg, qd, suspension in $0.5 \%$ CMC-Na) for 21 days, respectively. CON rats only received an equivalent volume of vehicle. The CDCA dose was designed according to previous reports $[38,39]$. The function of intestinal PepT1 in rats was assessed using oral pharmacokinetics of cephalexin on the 14th day and the 21st day during CDCA treatment. Expression of intestinal PepT1 protein in rats was measured at $24 \mathrm{~h}$ after the last dose.

Western blot

The protein levels of PepT1 and FXR in rat jejunum and Caco-2 cells were measured by Western blot. The samples were obtained by RIPA lysis buffer containing $1 \mathrm{mM}$ phenylmethyl sulfonylfluoride. Protein concentrations were determined by a BCA protein assay kit. Sodium dodecyl sulfate-polyacrylamide gel (8\%) electrophoresis separated equal amounts of proteins that were transferred to polyvinylidene fluoride membranes (Millipore, Billerica, MA, USA). Protein was blocked in 5\% skim milk Tris-buffered saline containing $0.1 \%$ Tween 20 (TBST) for $2 \mathrm{~h}$ at room temperature. The membranes were washed with TBST and incubated overnight with primary antibodies against PepT1 (1:1000 dilution), FXR (1:5000) and $\beta$-actin (1:3000 dilution) at $4{ }^{\circ} \mathrm{C}$. Following washing in TBST, the membranes were incubated with a horseradish peroxidase-conjugated secondary antibody (1:5000 dilution) (Bioworld Technology, Bloomington, MN, USA) for $2 \mathrm{~h}$. The protein levels were detected by Tanon highsig ECL Western blotting substrate (Thermo Fisher Scientific, Waltham, MA, USA) using a gel imaging system (Tanon 5200 Multi Chemiluminescent System, Shanghai, China). All protein levels were normalized to $\beta$-actin.

\section{Drug analysis}

Concentrations of cephalexin in rat plasma and perfusate were determined by LC-MS and HPLC, respectively [40]. The linear ranges of cephalexin in plasma and perfusion buffer were $19.5-5000 \mathrm{ng} / \mathrm{mL}$ and $31.25-200 \mu \mathrm{M}$, respectively.

Concentrations of acyclovir in rat plasma were determined by a validated HPLC-FLU method [7]. The wavelengths for fluorescence detection were set at $270 \mathrm{~nm}$ (excitation wavelength) and $360 \mathrm{~nm}$ (emission wavelength). The line range of acyclovir in plasma was $36.6-18750 \mathrm{ng} / \mathrm{mL}$.

Concentrations of bile acids in the intestinal contents were determined by LC-MS [41]. Standard curve linear ranges were $0.78-100 \mu \mathrm{g} / \mathrm{mL}$ for CA and GCA $1.56-200 \mu \mathrm{g} / \mathrm{mL}$ for LCA, $3.15-200 \mu \mathrm{g} / \mathrm{mL}$ for HDCA, $7.8-1000 \mu \mathrm{g} / \mathrm{mL}$ for CDCA and $15.6-2000 \mu \mathrm{g} / \mathrm{mL}$ for DCA. The samples beyond the range of the standard curve were diluted.

Statistical analysis

All data are expressed as the mean \pm standard deviation (SD). The pharmacokinetic parameters were estimated by Pheonix Winnonlin 8.1 (Pharsight, St Louis, MO, USA) using noncompartmental analysis. Statistical analysis among groups was calculated using one-way analysis of variance (ANOVA) followed by Tukey's post hoc test. A $P<0.05$ was regarded as statistically significant.

\section{RESULTS}

Induction of diabetic rats

DM rats induced by the combination of a high-fat diet and a low dose of STZ were confirmed by biochemical parameters on the 7th day after STZ injection (Table 1). The results showed that the $\mathrm{DM}$ rats were characterized by polydipsia, polyphagia, polyuria, lower weight gain, lower FINS and higher FGB, TC, TG, and HOMAIR levels and liver weight.

Pharmacokinetics of cephalexin and acyclovir in experimental rats after oral administration

Plasma concentrations of cephalexin and acyclovir were determined following oral administration of cephalexin (Fig. 1a) and valacyclovir (Fig. 1b) to experimental rats. Corresponding pharmacokinetic parameters were estimated (Table 2). The results showed that diabetes significantly decreased plasma concentrations of cephalexin following oral administration, leading to decreases in peak concentration $\left(C_{\max }\right)$ and area under curve (AUC) by $20 \%$ and $16.4 \%$ of the control, respectively. In contrast to plasma exposure, a longer half-life $\left(t_{1 / 2}\right)$ of cephalexin was observed in DM rats, indicating that elimination of cephalexin was delayed and that the decrease in plasma exposure mainly came from impairment of intestinal absorption. Valacyclovir, a prodrug, is hydrolyzed to acyclovir. In line with the findings for 
Table 1. Physiological and biochemical parameters of DM, HFD and CON rats at the 7th day following streptozotocin injection

\begin{tabular}{|c|c|c|c|}
\hline Parameters & DM & HFD & CON \\
\hline $\begin{array}{l}\text { Body weight } \\
\text { (BW) (g) }\end{array}$ & $269.71 \pm 13.10^{* \# \#}$ & $313.86 \pm 14.78^{* *}$ & $287.29 \pm 12.96$ \\
\hline $\begin{array}{l}\text { Liver } \\
\text { weight (\% BW) }\end{array}$ & $6.93 \pm 0.52^{* * \# \#}$ & $5.28 \pm 0.30^{* *}$ & $2.42 \pm 0.08$ \\
\hline FGB (mM) & $24.94 \pm 1.61^{* * \# \#}$ & $5.53 \pm 0.33$ & $5.79 \pm 0.46$ \\
\hline FINS (mIU/L) & $30.68 \pm 4.78^{* * \#}$ & $42.03 \pm 10.16$ & $52.34 \pm 8.41$ \\
\hline HOMA-IR & $33.99 \pm 5.71^{* * \# \#}$ & $10.43 \pm 3.03$ & $13.56 \pm 2.92$ \\
\hline $\mathrm{TC}(\mathrm{mM})$ & $5.44 \pm 1.83^{* * \# \#}$ & $2.72 \pm 0.51^{* *}$ & $1.19 \pm 0.14$ \\
\hline TG (mM) & $1.72 \pm 0.45^{* * \# \#}$ & $0.81 \pm 0.11^{* *}$ & $0.51 \pm 0.10$ \\
\hline \multicolumn{4}{|c|}{$\begin{array}{l}\text { Data are presented as mean } \pm \mathrm{SD}(n=6) \\
C O N \text { control rats, DM diabetic rats, FGB fasting glucose in blood, FINS } \\
\text { fasting insulin level, HFD high-fat-diet rats, HOMA-IR homeostasis model } \\
\text { assessment-insulin resistance, TC total cholesterol level, TG total } \\
\text { triglyceride level } \\
{ }^{*} P<0.05 \text { and }{ }^{* *} P<0.01 \text { vs CON rats, }{ }^{\#} P<0.05 \text { and }{ }^{\# \#} P<0.01 \text { vs HFD rats }\end{array}$} \\
\hline
\end{tabular}

cephalexin, DM rats showed lower plasma concentrations of acyclovir accompanied by lower plasma exposure than CON rats. Similarly, DM rats showed a longer $t_{1 / 2}$ of acyclovir, although no significance was obtained. Feeding with high-fat diets only slightly affected the oral pharmacokinetics of the two PepT1 substrates.

Intestinal absorption of cephalexin and expression of PepT1 in rats The intestinal absorption of cephalexin in the jejunum was measured to evaluate the function of intestinal PepT1 in DM rats, CON rats and HFD rats (Fig. 1c). In line with the oral pharmacokinetics of cephalexin, DM rats showed significantly reduced intestinal absorption of cephalexin, evidenced by lower $P_{\text {eff, }}$ inferring the impaired function of intestinal PepT1. Consistently, significantly reduced expression of intestinal PepT1 protein was found in DM rats, whose expression was only $45 \%$ that of CON rats (Fig. 1d). Feeding with a high-fat diet had little effect on the expression and function of intestinal PepT1 protein.

Effects of bile acids on the expression of PepT1 in Caco-2 cells The effects of six bile acids (DCA, CDCA, LCA, HDCA, CA and GCA) on the expression of PepT1 in Caco-2 cells were investigated (Fig. 2a). The results demonstrated that all of the tested bile acids decreased the expression of PepT1 proteins, among which CDCA showed the strongest inhibition, followed by HDCA and DCA. The levels of DCA, CDCA, LCA, CA, HDCA and GCA in the small intestines of rats were also measured (Fig. 1e). It was found that alterations in these bile acids under diabetic conditions were greatly different. Compared with CON rats, DM rats exhibited remarkably higher levels of CDCA, CA and GCA but lower levels of LCA and HDCA in the small intestine contents. The levels of DCA in the small intestine contents of DM rats were comparable to those in CON rats. Thus, CDCA was selected as a representative bile acid to investigate the role of bile acids in the expression of intestinal PepT1. CDCA concentration-dependent inhibition was observed (Fig. 3a), and a significant decrease occurred at $50 \mu \mathrm{M}$ and $100 \mu \mathrm{M}$ concentrations. A higher concentration of CDCA was not documented due to its cytotoxicity.

The effects of other factors, including gemfibrozil, insulin, LPS, SCFAs and TNF-a, on the expression of PepT1 protein were also documented (Fig. 2b-f). The results showed that gemfibrozil (Fig. 2b), insulin (Fig. 2c), LPS (Fig. 2d) and TNF-a (Fig. 2f) had little effect on the expression of PepT1 protein, while SCFAs increased the expression of PepT1 protein (Fig. 2e). Importantly, CDCA still remarkably downregulated the expression of PepT1 protein in Caco-2 cells cotreated with gemfibrozil, insulin, LPS, SCFAs and TNF-a.
Involvement of FXR activation in CDCA-mediated suppression of PepT1 protein in Caco-2 cells

The involvement of FXR activation in CDCA-mediated PepT1 suppression in Caco-2 cells was documented using both the FXR inhibitor MCA and siRNA targeting FXR. The results showed that CDCA-mediated downregulation of PepT1 expression in Caco-2 cells was remarkably reversed by MCA (Fig. 3b). GW4064, another FXR agonist, also suppressed the expression of PepT1 protein, which was also attenuated by MCA (Fig. 3c). The role of FXR in CDCA-mediated downregulation of PepT1 expression was further confirmed using FXR knockdown with siRNA targeting FXR. It was found that expression of FXR protein in Caco-2 cells transfected with FXR siRNA was decreased to $20 \%$ of that of control cells, inferring successful silencing of FXR (Fig. 3d). This result was consistent with our expectation that the CDCA-induced decrease in PepT1 protein was attenuated by FXR siRNA (Fig. 3e). GW4064 no longer downregulated the expression of PepT1 protein in Caco-2 cells transfected with FXR siRNA (Fig. 3f). Moreover, FXR knockdown with siRNA induced the expression of PepT1 protein in Caco-2 cells (Fig. 3e, f). Furthermore, the expression of intestinal FXR in DM rats was also measured. This result was consistent with our expectations that DM significantly induced the expression of intestinal FXR protein (Fig. 1f), which was negatively associated with the expression of intestinal PepT1 protein.

Effect of CDCA on pharmacokinetics of cephalexin and expression of PepT1 in rats

On the 14th day and the 21 st day during CDCA treatment, plasma concentrations of cephalexin (Fig. 4a, b) were determined following oral administration of cephalexin to rats, and corresponding pharmacokinetic parameters were estimated (Table 3 ). The results showed that on the 14th day (Fig. 4a), compared with the CON condition, treatment with a high dose of CDCA significantly reduced $C_{\max }$ and AUC values of cephalexin in rats. The rats treated with a low dose of CDCA also showed trends in $C_{\max }$ and AUC, although no significance was found. On the 21st day (Fig. 4b), rats treated with low dose or high dose of CDCA showed sharp decreases in $C_{\max }$ and AUC values of cephalexin, but no dose dependence was observed. The levels of intestinal PepT1 in rats were measured (Fig. 4c). Consistent with alterations in the pharmacokinetics of cephalexin, treatment with CDCA remarkably downregulated the expression of intestinal PepT1 protein in rats, but no dose-dependent inhibition was found.

\section{DISCUSSION}

Several studies have demonstrated that diabetes alters the expression and function of intestinal PepT1 in rats [18$21,24,42]$, although the results are often confusing. Moreover, the real mechanisms resulting in alterations in the expression of intestinal PepT1 are not clearly understood. The main aim of the present study was to further investigate alterations in the expression and function of intestinal PepT1 and the real mechanisms underlying diabetic conditions using both diabetic rats and Caco- 2 cells. Diabetic rats were induced by a combination of a high-fat diet and a low dose of STZ. The induced diabetic rats were characterized by diabetic symptoms, such as hyperglycemia, dyslipidemia, polyuria, polydipsia, lower FINS and higher liver weight and levels of TC, TG and HOMA-IR, demonstrating successful development of diabetic rats. Two widely used PepT1 substrates, cephalexin $[2,4,43]$ and valacyclovir $[7,44,45]$, were used to assess the function of intestinal PepT1 in rats. Compared with CON rats, DM rats showed lower plasma exposure of cephalexin and acyclovir following oral administration. Moreover, the extent of the decreases in $C_{\max }$ was larger than the extent of those in $A U C$, demonstrating impairment of intestinal absorption. Data from in situ single-pass perfusion demonstrated 
a

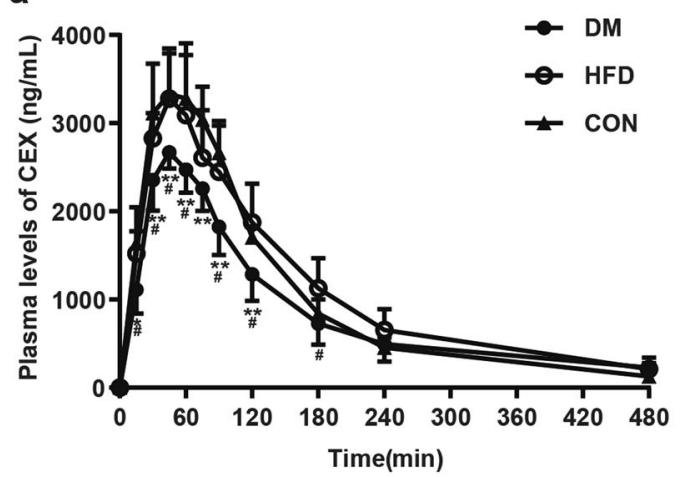

C



e



b

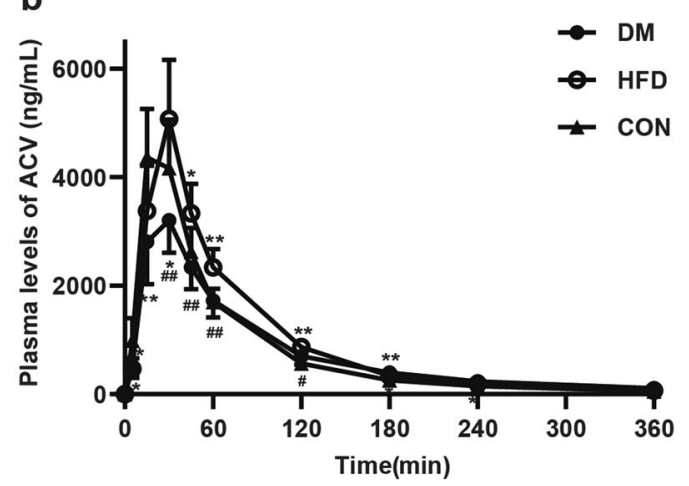

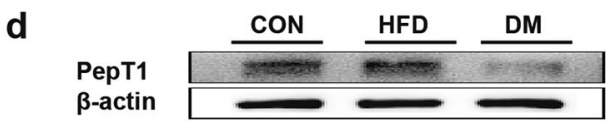



f



$\beta$-actin

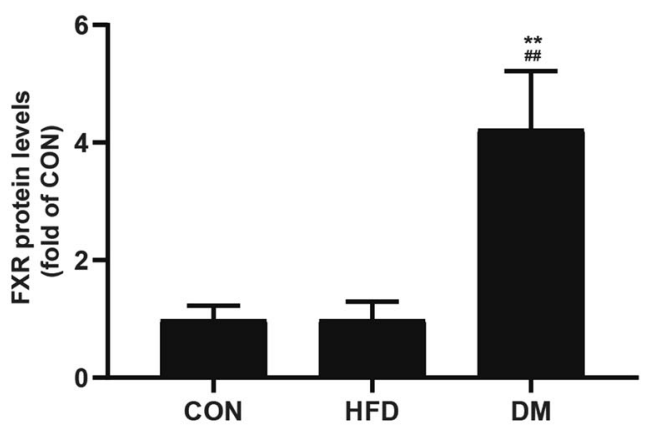

Fig. 1 Effect of diabetes on the expression and function of PepT1 and the concentrations of bile acids in the intestinal contents. Plasma concentrations of cephalexin (a) following oral administration of cephalexin $(5 \mathrm{mg} / \mathrm{kg})$ and plasma concentrations of acyclovir (b) following oral administration of valacyclovir $(18.4 \mathrm{mg} / \mathrm{kg})$ to CON, HFD and DM rats. The $P_{\text {eff }}$ values (c) in the intestine using single-pass intestinal perfusion with cephalexin $(40 \mu \mathrm{M})$ and protein levels of PepT1 (d) in the jejunum of CON, HFD and DM rats. Concentrations of deoxycholic acid (DCA), chenodeoxycholic acid (CDCA), lithocholic acid (LCA), cholic acid (CA), hyodeoxycholic acid (HDCA), and glycocholic acid (GCA) (e) in intestinal contents in CON, HFD and DM rats. Expression of FXR protein in the jejunum of CON, HFD and DM rats (f). Data are presented as the mean \pm SD $(n=6) .{ }^{*} P<0.05$ and ${ }^{* *} P<0.01$ vs CON rats, ${ }^{\#} P<0.05$ and ${ }^{\# \#} P<0.01$ vs HFD rats

that the $P_{\text {eff }}$ of cephalexin across the intestinal wall of diabetic rats was significantly lower than that of CON rats, which was associated with decreased expression of intestinal PepT1 protein. Cephalexin and acyclovir are mainly eliminated via urinal excretion, accounting for $80 \%$ to $93.5 \%$ [46] and 95\% [47] of the intravenous dose, respectively, indicating that the roles of CYP450s in the disposition of cephalexin and acyclovir are minor although the activities and expression of CYP450s are also altered by diabetes. Renal PepT1/2 and organic anion transporter $1 / 3$ (OAT1/3) mediate renal excretion of cephalexin. Renal multidrug resistance-associated protein $2(\mathrm{MRP} 2)$ and OAT1/3 also mediate renal excretion of acyclovir $[14,48]$. Generally, OAT1/3, expressed in the basolateral membrane of tubules, mediates secretion of their substrates. PepT1/2 and MRP2 are located in the brushborder membrane of tubules and mediate reabsorption and efflux of their substrates, respectively [14]. Diabetes was also reported to increase the expression of renal PepT1 [49] and MRP2 [50] but downregulate the expression of renal OAT1/3 [51, 52]. The downregulation of renal OAT1/3 and upregulation of renal PepT1 by diabetes may partly explain why DM rats showed a longer $t_{1 / 2}$ 
Table 2. Pharmacokinetic parameters of cephalexin and acyclovir following oral administration of cephalexin $(5 \mathrm{mg} / \mathrm{kg})$ and valacyclovir (18.4 mg/kg) to rats

\begin{tabular}{|c|c|c|c|c|c|c|}
\hline & \multicolumn{3}{|l|}{ Cephalexin } & \multicolumn{3}{|l|}{ Acyclovir } \\
\hline$t_{1 / 2}(\mathrm{~h})$ & $2.53 \pm 0.77^{*}$ & $1.92 \pm 0.41$ & $1.47 \pm 0.52$ & $1.74 \pm 0.51$ & $1.27 \pm 0.46$ & $1.30 \pm 0.82$ \\
\hline$T_{\max }(\mathrm{h})$ & $0.75 \pm 0.14$ & $0.82 \pm 0.19$ & $0.82 \pm 0.19$ & $0.43 \pm 0.12$ & $0.46 \pm 0.09$ & $0.36 \pm 0.13$ \\
\hline$C_{\max }(\mu \mathrm{g} / \mathrm{mL})$ & $2.72 \pm 0.17^{* * \# \#}$ & $3.42 \pm 0.56$ & $3.60 \pm 0.61$ & $3.31 \pm 0.60^{* * \# \#}$ & $5.09 \pm 1.08$ & $4.57 \pm 0.78$ \\
\hline$A \cup C_{\text {last }}(\mathrm{h} \cdot \mu \mathrm{g} / \mathrm{mL})$ & $6.79 \pm 0.90^{* * \#}$ & $8.85 \pm 2.01$ & $8.12 \pm 0.63$ & $4.34 \pm 0.79$ & $5.89 \pm 0.54^{* *}$ & $4.89 \pm 0.04$ \\
\hline
\end{tabular}

of cephalexin. Similarly, the longer $t_{1 / 2}$ of acyclovir in DM rats seemed to be attributed to the downregulation of renal OAT1/3. The above results indicated that the altered expression of renal transporters by diabetes did not decrease plasma exposure to cephalexin and acyclovir, further confirming that decreases in oral plasma exposure to cephalexin and acyclovir under diabetic conditions were mainly attributed to the downregulation of intestinal PepT1. The present study confirmed remarkable downregulation of PepT1 expression and function in the intestine of DM rats, which was consistent with previous reports [18-20, 24], although two contrary reports were found [21, 42]. The discrepancies seemed to result from the strain and sex of the animals as well as the treatment. For example, in SD rats, it was reported that STZ-induced diabetes decreased the expression and function of intestinal PepT1 in male rats but increased it in female rats [19]. In male Wistar rats, STZ-induced diabetes slightly affected the expression and function of intestinal PepT1. However, Zucker-fa/fa rats and male GK Jcl rats showed higher expression and function of intestinal PepT1 than Wistar control rats [21].

Next, we investigated real mechanisms downregulating the expression of intestinal PepT1 using Caco- 2 cells, an in vitro model of the intestinal system. A series of studies have demonstrated that diabetes may alter the intestinal environment, such as increases in the levels of SCFAs [18], dyshomeostasis of bile acids [26-29] and alterations in the gut microbiome [53]. The effects of these factors, such as bile acids (GCA, CA, LCA, CDCA, DCA and HDCA), SCFAs, LPS, TNF- $a$ and insulin, on the expression of PepT1 protein were investigated. The findings was in contrast to our expectation that LPS, TNF-a and insulin could not affect the expression of PepT1. SCFAs induced rather than decreased expression of PepT1 protein, which was reversed by CDCA. All these findings at least partly excluded contributions of the three factors (LPS, TNF-a and SCFAs) from downregulation of intestinal PepT1 by diabetes. However, reports about the role of insulin in the regulation of PepT1 expression are confusing. In Caco-2 cells, it was reported that short-term insulin treatment enhanced the expression of PepT1 protein on the apical membrane and its function without affecting the level of PepT1 mRNA [25, 34]. Insulin decreased the expression of intestinal PepT1 mRNA and protein in nondiabetic male rats [19] but increased the expression of intestinal PepT1 in diabetic male rats $[19,51]$. Importantly, the insulin-induced alterations in female rats were in contrast to those in male rats [19]. Thus, the role of insulin in the expression of intestinal PepT1 needs further investigation.

All six of the tested bile acids decreased the expression of PepT1 protein, and CDCA showed the strongest inhibition. High levels of CDCA, CA, GCA and DCA were also detected in the intestinal contents of rats. Moreover, diabetes increased the levels of intestinal CDCA, CA and GCA. The extent of increase in CDCA level was also the highest among the three bile acids. Thus, CDCA was selected to further document the role of bile acids in the downregulation of PepT1 expression.

Bile acids, including CDCA, are natural ligands of FXR and achieve their effects by activating FXR [30]. A series of experiments were designed to investigate whether CDCA downregulated PepT1 by activating FXR. The result was consistent with our expectation that two FXR agonists, CDCA and GW4064, decreased the expression of PepT1 protein in Caco-2 cells, which could be reversed by the FXR inhibitor MCA and FXR siRNA. In addition, knockdown of FXR itself induced expression of the PepT1 protein. All these results inferred that CDCA downregulated the expression of PepT1 protein by activating FXR. A mouse experiment showed that feeding with $0.5 \%$ CA for 5 days did not affect the mRNA level of intestinal PepT1, but the expression of intestinal PepT1 in $\mathrm{FXR}^{-1-}$ mice was higher than that in wild-type mice [54]. These results support the involvement of FXR activation in the altered expression of intestinal PepT1 by bile acids. Data in vivo also showed a negative association of intestinal Pept1 protein and expression of intestinal FXR, and it was considered that activation of FXR suppresses expression of intestinal CYP7A1 via FXR-FGF15 signaling [55]. Noticeable activation of FXR-FFG15 signaling by diabetes was observed in the ileum of mice [56], which inferred that downregulation of Pept1 protein expression by CDCA may also be involved in FXR-FFG15 signaling, which requires further investigation. In addition, PepT1 is considered a typical target gene of peroxisome proliferator-activated receptor a (PPARa) $[57,58]$. Both in vivo and in vitro data demonstrated that the PPARa ligand WY-14643 induced the expression of PepT1 $[57,58]$. In Caco-2 cells, CA concentration-dependently inhibited WY14643-induced expression of PepT1, and significant inhibition occurred at $500 \mu \mathrm{M} \mathrm{CA}$, which led to the conclusion that CA downregulated PepT1 expression by inhibiting PPARa [57]. However, the role of PPARa in the expression of PepT1 has not been replicated in other studies $[22,59,60]$. Our results showed that the PPARa ligand gemfibrozil slightly reversed the CDCAinduced downregulation of PepT1 expression. Whether CDCA downregulated PepT1 expression by inhibiting PPARa requires further investigation.

The role of CDCA in the regulation of intestinal PepT1 expression in vivo was assessed using the pharmacokinetics of cephalexin following oral administration of cephalexin to rats treated with CDCA. CDCA treatment significantly reduced oral plasma exposure to cephalexin, especially the $C_{\max }$ and AUC, which were accompanied by a significant decrease in the expression of PepT1 protein, demonstrating CDCA-mediated downregulation of intestinal PepT1. Significantly increased CDCA levels were also observed in the intestinal contents of diabetic rats, which indicated that the downregulation of intestinal PepT1 
a

CON LCA GCA CDCA HDCA DCA CA

PepT1 $\$ \ldots$

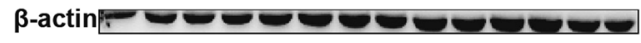



C
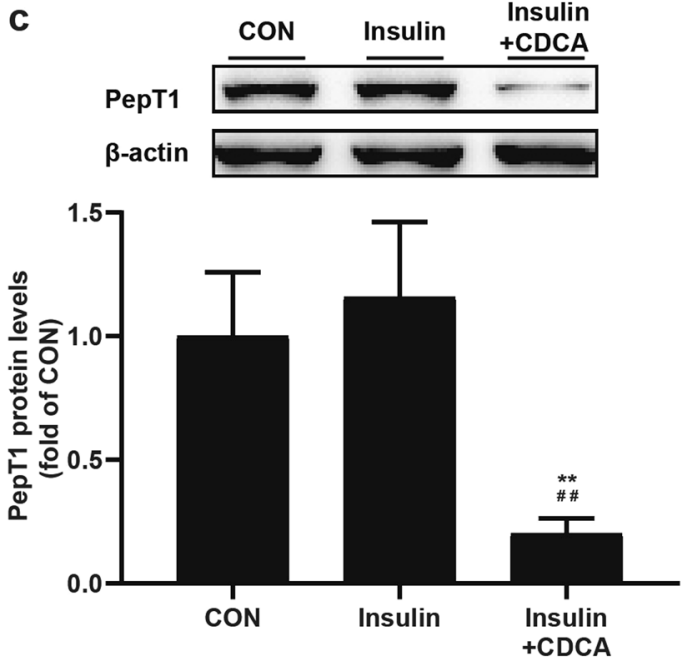

e
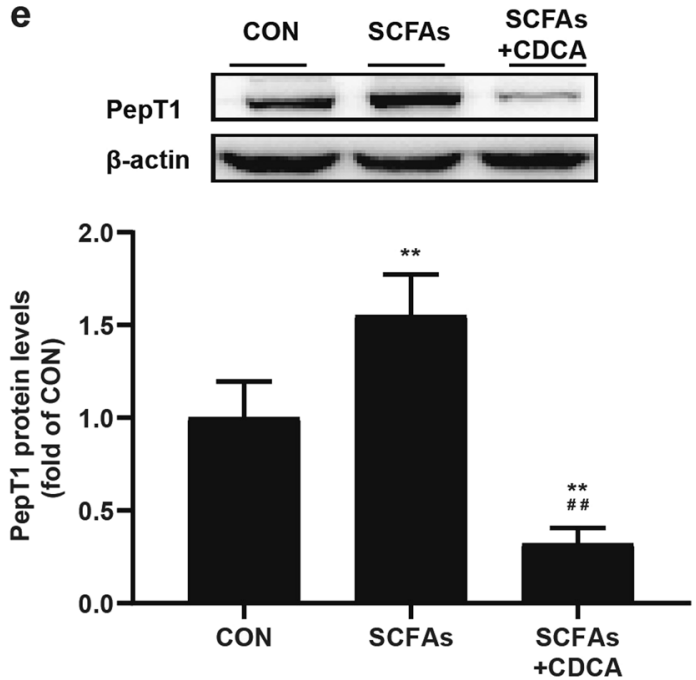

b
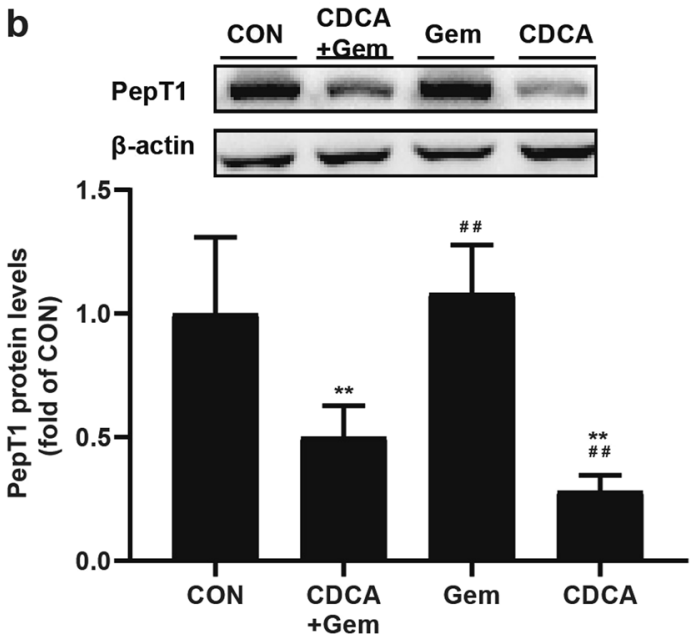

d


$\mathbf{f}$
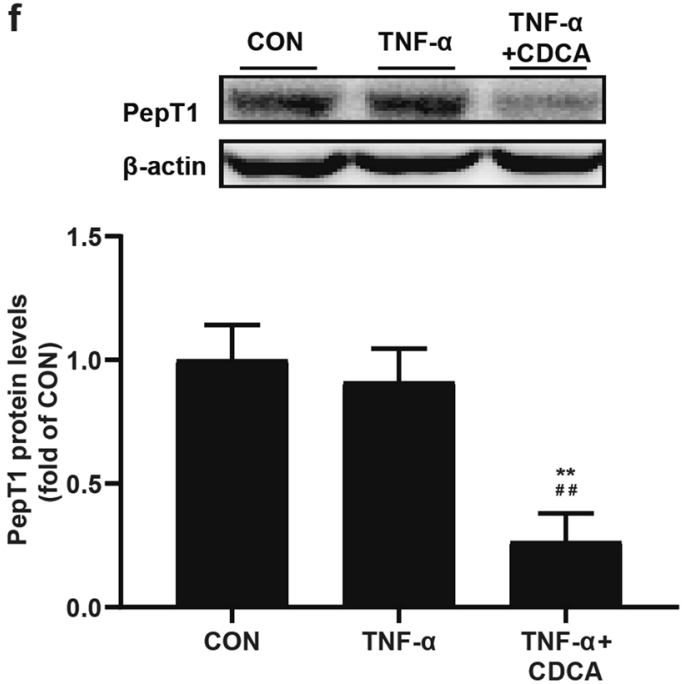

Fig. 2 Effect of potential factors on the expression of PepT1 in Caco-2 cells. Protein levels of PepT1 in Caco-2 cells treated with lithocholic acid (LCA), glycocholic acid (GCA), chenodeoxycholic acid (CDCA), hyodeoxycholic acid (HDCA), deoxycholic acid (DCA) and cholic acid (CA) (a), gemfibrozil (Gem) (b), insulin (c), lipopolysaccharide (LPS) (d), short-chain fatty acids (SCFAs) (e) and tumor necrosis factor- $\alpha$ (TNF- $\alpha$ ) (f). Data are presented as the mean \pm SD $(n=6)$. ${ }^{*} P<0.01$ vs CON. ${ }^{*} P<0.01$ vs CDCA + Gem or Insulin or LPS or SCFAs or TNF- $\alpha$ 
a
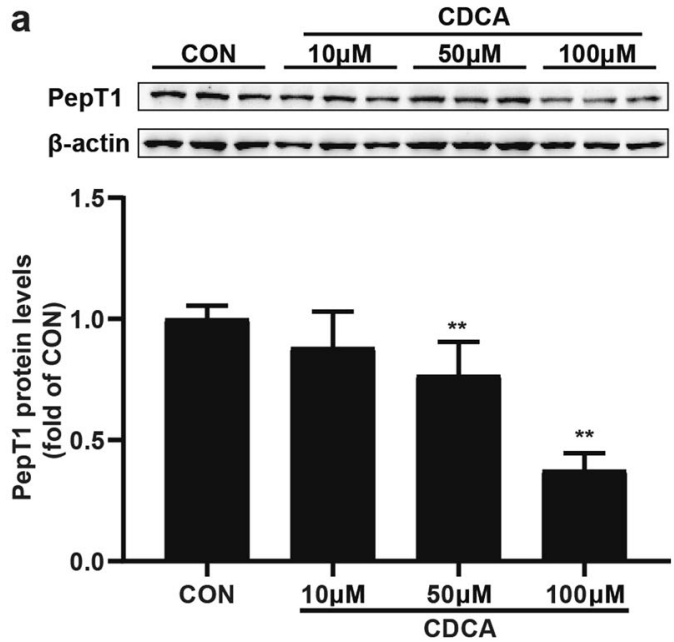

c
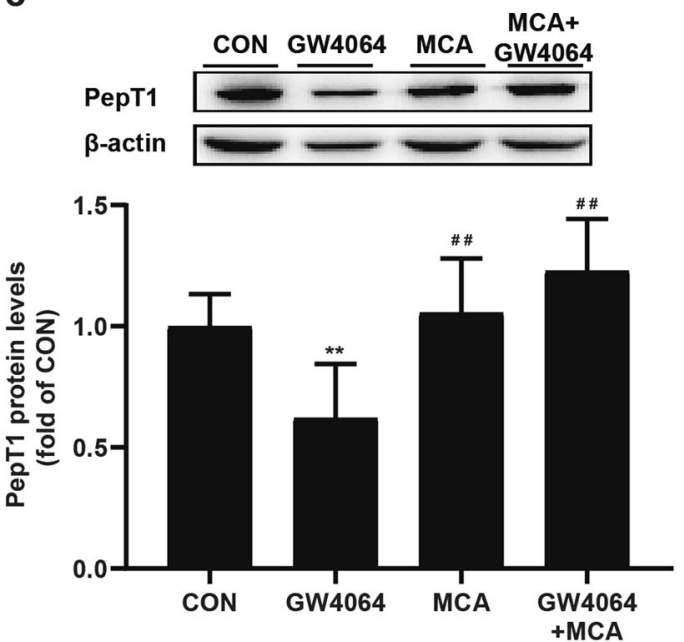

e

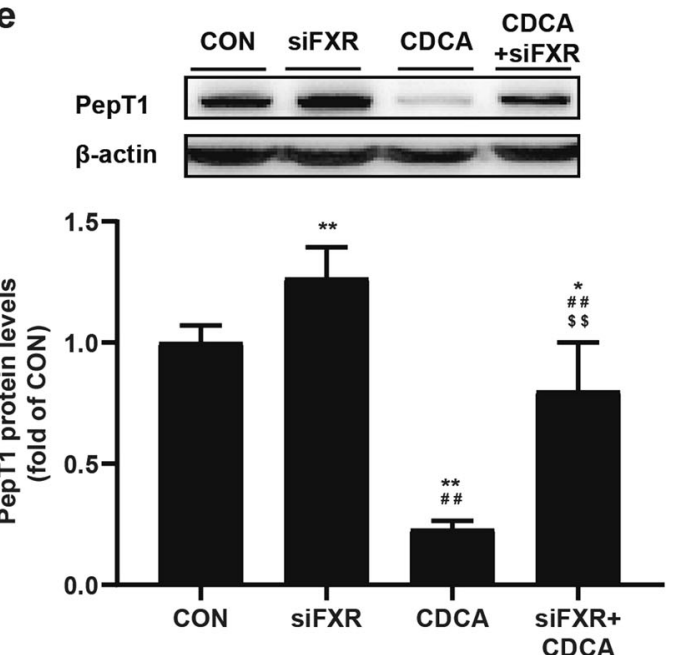

b
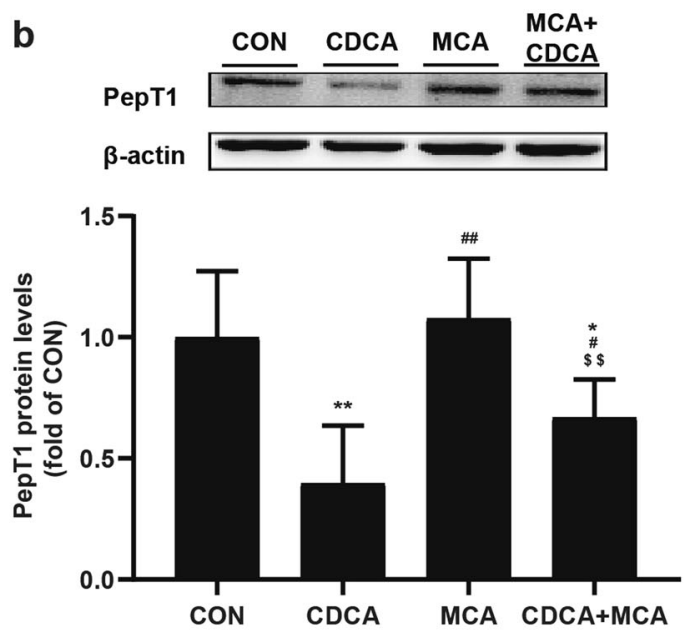

d
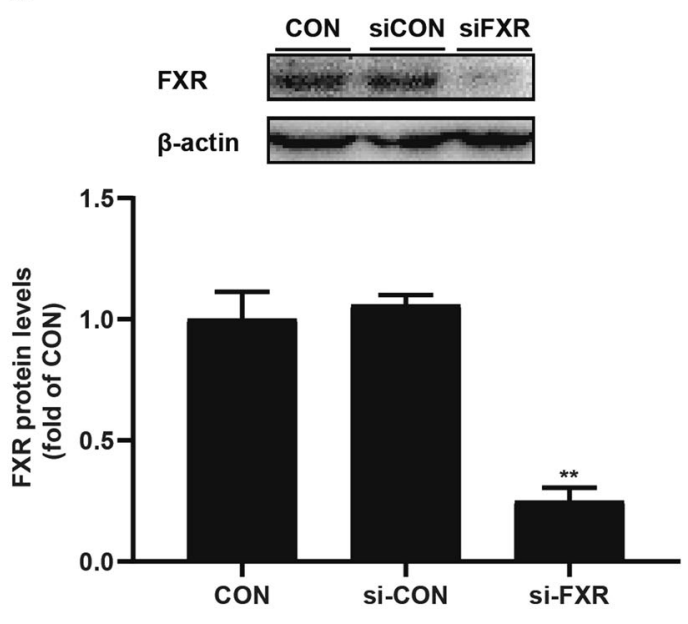

$\mathbf{f}$
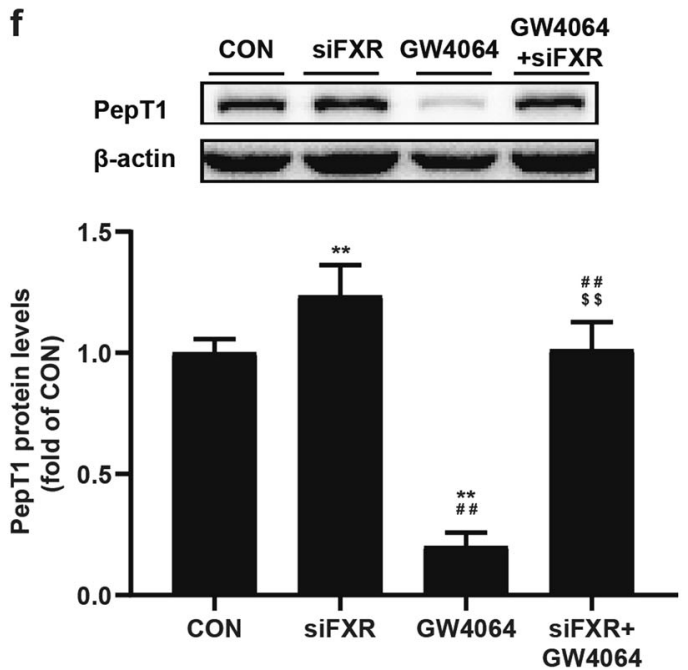

Fig. 3 Effect of CDCA or FXR on the expression of PepT1 in Caco-2 cells. Protein levels of PepT1 in Caco-2 cells treated with different concentrations of CDCA (a), FXR inhibitor glycine- $\beta$-muricholic acid (MCA) (b), FXR agonist GW4064 (c). Effect of FXR knockdown on FXR expression (d) and PepT1 expression treated with CDCA (e) and GW4064 (f). Data are presented as the mean \pm SD $(n=6)$. ${ }^{*} P<0.05$ and ${ }^{* *} P<$ 0.01 vs CON. ${ }^{\#}<0.05$ and ${ }^{\# \#} P<0.01$ vs CDCA, GW4064 or siFXR. ${ }^{\$ \$} P<0.01$ vs CDCA or GW4064 
a



C

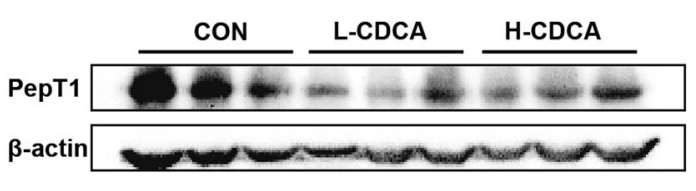

b
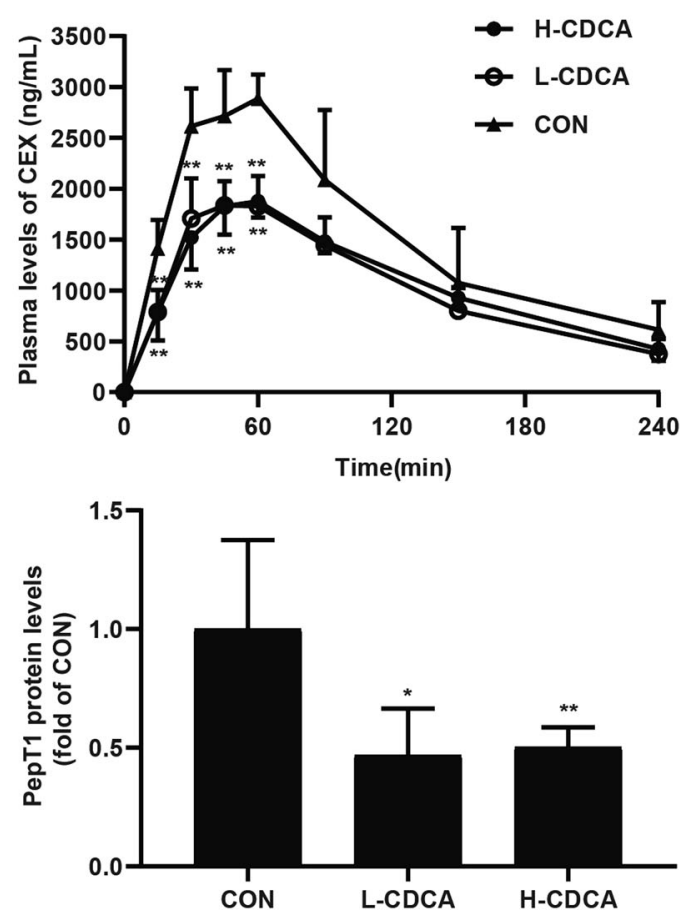

Fig. 4 Effect of CDCA on pharmacokinetics of cephalexin (CEX) and expression of PepT1 in rats. Plasma concentrations of cephalexin following oral administration of cephalexin $(5 \mathrm{mg} / \mathrm{kg})$ to CON, L-CDCA and H-CDCA rats on the 14th day (a) and $21 \mathrm{st}$ day (b) during administration of CDCA. Protein levels of PepT1 (c) in the jejunum of CON, L-CDCA and H-CDCA rats. Data are presented as the mean \pm SD $(n=6) .{ }^{*} P<0.05$ and ${ }^{* *} P<0.01$ vs CON rats. ${ }^{\#} P<0.05$ and ${ }^{\sharp} P<0.01$ vs L-CDCA rats

Table 3. Pharmacokinetic parameters of cephalexin following oral administration of cephalexin $(5 \mathrm{mg} / \mathrm{kg})$ to rats on the 14 th day and $21 \mathrm{st}$ day during CDCA treatment

\begin{tabular}{|c|c|c|c|c|c|c|}
\hline & $\mathrm{H}-\mathrm{CDCA}$ & $\mathrm{L}-\mathrm{CDCA}$ & CON & $\mathrm{H}-\mathrm{CDCA}$ & $\mathrm{L}-\mathrm{CDCA}$ & CON \\
\hline$T_{\max }(\mathrm{h})$ & $0.71 \pm 0.10$ & $0.63 \pm 0.14$ & $0.63 \pm 0.14$ & $0.9 \pm 0.14$ & $0.79 \pm 0.19$ & $0.75 \pm 0.22$ \\
\hline$C_{\max }(\mu \mathrm{g} / \mathrm{mL})$ & $2.72 \pm 0.38^{* \#}$ & $3.30 \pm 0.37$ & $3.71 \pm 0.71$ & $1.92 \pm 0.20^{* *}$ & $2.02 \pm 0.39^{* *}$ & $2.88 \pm 0.38$ \\
\hline$A \cup C_{\text {last }}(\min \cdot \mu \mathrm{g} / \mathrm{mL})$ & $4.61 \pm 0.22^{* * \#}$ & $5.52 \pm 0.68$ & $5.93 \pm 0.87$ & $4.33 \pm 0.43^{*}$ & $4.34 \pm 0.89^{*}$ & $5.92 \pm 1.26$ \\
\hline
\end{tabular}

in diabetic rats was partly attributed to the increased levels of intestinal CDCA. In line with the findings in rats, a clinical trial also showed lower levels of ampicillin in diabetic patients [61]. In addition to peptidomimetic drugs, intestinal PepT1 also mediates intestinal absorption of endogenous substances such as peptides resulting from dietary breakdown of proteins [12] and bacterial peptidomimetics [14]. The downregulation of intestinal PepT1 seemed to prevent intestinal absorption of bacterial peptidomimetics. Moreover, PepT1 deficiency also prevented weight gain and improved energy metabolism [12, 13]. These results indicate that the clinical significance of alterations in the expression and functions of intestinal PepT1 under diabetic conditions requires further investigation.

In conclusion, diabetes remarkably downregulated the expression of intestinal PepT1 in rats and increased the levels of intestinal CDCA. CDCA impaired PepT1 protein expression partly by activating FXR.

\section{ACKNOWLEDGEMENTS}

This work was supported by the National Natural Science Foundation of China (Nos. $81872930,81673505$ and 81573490$)$ and the "Double First-Class" university project (No. CPU2018GY22).

\section{AUTHOR CONTRIBUTIONS}

$L M L, F X$ and XDL designed the research. LML, JJZ, FX, LQ, PHL completed the experiments. $L M L, X D L$ analyzed the data. $L M L$ and $X D L$ wrote the manuscript. $L M L$, $\mathrm{LL}$ and $\mathrm{XDL}$ reviewed the manuscript.

\section{ADDITIONAL INFORMATION}

Competing interests: The authors declare no competing interests. 


\section{REFERENCES}

1. Tamai I, Nakanishi T, Hayashi K, Terao T, Sai Y, Shiraga T, et al. The predominant contribution of oligopeptide transporter PepT1 to intestinal absorption of beta-lactam antibiotics in the rat small intestine. J Pharm Pharmacol. 1997;49:796-801.

2. Hu Y, Smith DE. Species differences in the pharmacokinetics of cefadroxil as determined in wildtype and humanized PepT1 mice. Biochem Pharmacol. 2016;107:81-90.

3. Buyse M, Berlioz F, Guilmeau S, Tsocas A, Voisin T, Peranzi G, et al. PepT1mediated epithelial transport of dipeptides and cephalexin is enhanced by luminal leptin in the small intestine. J Clin Invest. 2001;108:1483-94.

4. Hironaka T, Itokawa S, Ogawara K, Higaki K, Kimura T. Quantitative evaluation of PEPT1 contribution to oral absorption of cephalexin in rats. Pharmacol Res. 2009;26:40-50.

5. Ogihara T, Kano T, Wagatsuma T, Wada S, Yabuuchi H, Enomoto S, et al. Oseltamivir (tamiflu) is a substrate of peptide transporter 1. Drug Metab Dispos. 2009;37:1676-81.

6. Yang B, Smith DE. In silico absorption analysis of valacyclovir in wildtype and Pept1 knockout mice following oral dose escalation. Pharmacol Res. 2017;34:2349-61.

7. Yang B, Smith DE. Significance of peptide transporter 1 in the intestinal permeability of valacyclovir in wild-type and PepT1 knockout mice. Drug Metab Dispos. 2013;41:608-14.

8. Poirier A, Belli S, Funk C, Otteneder MB, Portmann R, Heinig K, et al. Role of the intestinal peptide transporter PEPT1 in oseltamivir absorption: in vitro and in vivo studies. Drug Metab Dispos. 2012;40:1556-65.

9. Yang B, Hu Y, Smith DE. Impact of peptide transporter 1 on the intestinal absorption and pharmacokinetics of valacyclovir after oral dose escalation in wild-type and PepT1 knockout mice. Drug Metab Dispos. 2013;41:1867-74.

10. Zhu $T$, Chen $X Z$, Steel $A$, Hediger MA, Smith DE. Differential recognition of ACE inhibitors in Xenopus laevis oocytes expressing rat PEPT1 and PEPT2. Pharmacol Res. 2000;17:526-32.

11. Knutter I, Wollesky C, Kottra G, Hahn MG, Fischer W, Zebisch K, et al. Transport of angiotensin-converting enzyme inhibitors by $\mathrm{H}+$ /peptide transporters revisited. J Pharmacol Exp Ther. 2008;327:432-41.

12. Kolodziejczak D, Spanier B, Pais R, Kraiczy J, Stelzl T, Gedrich K, et al. Mice lacking the intestinal peptide transporter display reduced energy intake and a subtle maldigestion/malabsorption that protects them from diet-induced obesity. Am J Physiol Gastrointest Liver Physiol. 2013;304:G897-907.

13. Do TT, Hindlet P, Waligora-Dupriet AJ, Kapel N, Neveux N, Mignon V, et al. Disturbed intestinal nitrogen homeostasis in a mouse model of high-fat dietinduced obesity and glucose intolerance. Am J Physiol Endocrinol Metab. 2014;306:E668-80.

14. Liu X. SLC family transporters. Adv Exp Med Biol. 2019;1141:101-202.

15. Chen $M$, Singh $A$, Xiao F, Dringenberg U, Wang J, Engelhardt $R$, et al. Gene ablation for PEPT1 in mice abolishes the effects of dipeptides on small intestinal fluid absorption, short-circuit current, and intracellular pH. Am J Physiol Gastrointest Liver Physiol. 2010;299:G265-74.

16. Dranse HJ, Waise TMZ, Hamr SC, Bauer PV, Abraham MA, Rasmussen BA, et al. Physiological and therapeutic regulation of glucose homeostasis by upper small intestinal PepT1-mediated protein sensing. Nat Commun. 2018;9:1118.

17. Diakogiannaki E, Pais R, Tolhurst G, Parker HE, Horscroft J, Rauscher B, et al. Oligopeptides stimulate glucagon-like peptide-1 secretion in mice through proton-coupled uptake and the calcium-sensing receptor. Diabetologia. 2013;56:2688-96.

18. Xu F, Zhu L, Qian C, Zhou J, Geng D, Li P, et al. Impairment of intestinal monocarboxylate transporter 6 function and expression in diabetic rats induced by combination of high-fat diet and low dose of streptozocin: involvement of butyrate-peroxisome proliferator-activated receptor-gamma activation. Drug Metab Dispos. 2019;47:556-66.

19. Der-Boghossian AH, Saad SR, Perreault C, Provost C, Jacques D, Kadi LN, et al. Role of insulin on jejunal PepT1 expression and function regulation in diabetic male and female rats. Can J Physiol Pharmacol. 2010;88:753-9.

20. Bikhazi AB, Skoury MM, Zwainy DS, Jurjus AR, Kreydiyyeh SI, Smith DE, et al. Effect of diabetes mellitus and insulin on the regulation of the PepT 1 symporter in rat jejunum. Mol Pharmacol. 2004;1:300-8.

21. Watanabe K, Terada K, Sato J. Intestinal absorption of cephalexin in diabetes mellitus model rats. Eur J Pharm Sci. 2003;19:91-8.

22. Losacco MC, de Almeida CFT, Hijo AHT, Bargi-Souza P, Gama P, Nunes MT, et al. High-fat diet affects gut nutrients transporters in hypo and hyperthyroid mice by PPAR-alpha independent mechanism. Life Sci. 2018;202:35-43.

23. Torelli Hijo AH, Coutinho CP, Alba-Loureiro TC, Moreira Leite JS, Bargi-Souza P, Goulart-Silva F. High fat diet modulates the protein content of nutrient transporters in the small intestine of mice: possible involvement of PKA and PKC activity. Heliyon. 2019;5:e02611.
24. Hindlet $\mathrm{P}$, Bado A, Farinotti R, Buyse $\mathrm{M}$. Long-term effect of leptin on $\mathrm{H}+$-coupled peptide cotransporter 1 activity and expression in vivo: evidence in leptindeficient mice. J Pharmacol Exp Ther. 2007;323:192-201.

25. Watanabe K, Terada K, Jinriki T, Sato J. Effect of insulin on cephalexin uptake and transepithelial transport in the human intestinal cell line Caco-2. Eur J Pharm Sci. 2004;21:87-95.

26. Zheng X, Huang F, Zhao A, Lei S, Zhang Y, Xie G, et al. Bile acid is a significant host factor shaping the gut microbiome of diet-induced obese mice. BMC Biol. 2017;15:120.

27. Watanabe K, Igarashi M, Li X, Nakatani A, Miyamoto J, Inaba Y, et al. Dietary soybean protein ameliorates high-fat diet-induced obesity by modifying the gut microbiotadependent biotransformation of bile acids. PLoS One. 2018;13:e0202083.

28. Zhao J, Zhang QL, Shen JH, Wang K, Liu J. Magnesium lithospermate B improves the gut microbiome and bile acid metabolic profiles in a mouse model of diabetic nephropathy. Acta Pharmacol Sin. 2019;40:507-13.

29. Nervi FO, Severin CH, Valdivieso VD. Bile acid pool changes and regulation of cholate synthesis in experimental diabetes. Biochim Biophys Acta. 1978;529:212-23.

30. Ali AH, Carey EJ, Lindor KD. Recent advances in the development of farnesoid $X$ receptor agonists. Ann Transl Med. 2015;3:5.

31. Zhong ZY, Sun BB, Shu N, Xie QS, Tang XG, Ling ZL, et al. Ciprofloxacin blocked enterohepatic circulation of diclofenac and alleviated NSAID-induced enteropathy in rats partly by inhibiting intestinal beta-glucuronidase activity. Acta Pharmacol Sin. 2016;37:1002-12.

32. Song $M$, Ye J, Zhang F, Su H, Yang X, He H, et al. Chenodeoxycholic acid (CDCA) protects against the lipopolysaccharide-induced impairment of the intestinal epithelial barrier function via the FXR-MLCK pathway. J Agric Food Chem. 2019;67:8868-74.

33. Li Y, Zhang J, Xu P, Sun B, Zhong Z, Liu C, et al. Acute liver failure impairs function and expression of breast cancer-resistant protein (BCRP) at rat blood-brain barrier partly via ammonia-ROS-ERK1/2 activation. J Neurochem. 2016;138:282-94.

34. Thamotharan M, Bawani SZ, Zhou X, Adibi SA. Hormonal regulation of oligopeptide transporter Pept-1 in a human intestinal cell line. Am J Physiol-Cell Ph. 1999;276:C821-6.

35. Kivisto KT, Zukunft J, Hofmann U, Niemi M, Rekersbrink S, Schneider S, et al. Characterisation of cerivastatin as a P-glycoprotein substrate: studies in Pglycoprotein-expressing cell monolayers and mdr1a/b knock-out mice. Naunyn Schmiedebergs Arch Pharmacol. 2004;370:124-30.

36. Jiang C, Xie C, Lv Y, Li J, Krausz KW, Shi J, et al. Intestine-selective farnesoid X receptor inhibition improves obesity-related metabolic dysfunction. Nat Commun. 2015;6:10166.

37. Katona BW, Cummins CL, Ferguson AD, Li T, Schmidt DR, Mangelsdorf DJ, et al. Synthesis, characterization, and receptor interaction profiles of enantiomeric bile acids. J Med Chem. 2007;50:6048-58.

38. Rahman K, Billington D. Effect of chenodeoxycholate feeding upon the biliary output of plasma membrane enzymes in the rat. Biochem Pharmacol. 1984;33:2231-8.

39. Bazzari FH, Abdallah DM, El-Abhar HS. Chenodeoxycholic acid ameliorates AICl3induced Alzheimer's disease neurotoxicity and cognitive deterioration via enhanced insulin signaling in rats. Molecules. 2019;24:1992.

40. Arakawa $H$, Ohmachi $T$, Ichiba $K$, Kamioka $H$, Tomono $T$, Kanagawa $M$, et al. Interaction of peptide transporter 1 with $D$-glucose and $L$-glutamic acid; possible involvement of taste receptors. J Pharm Sci. 2016;105:339-42.

41. Yang T, Wang S, Liu P, Xu J, Liu X, Liu L. Influence on compatibility of Glycyrrhiza uralensis and Laminaria japonica on liver and kidney functions and serum indexes in rats. Chin Tradit Herb Drugs. 2018;49:1860-5.

42. Gangopadhyay A, Thamotharan M, Adibi SA. Regulation of oligopeptide transporter (Pept-1) in experimental diabetes. Am J Physiol Gastrointest Liver Physiol. 2002;283:G133-8.

43. Posada MM, Smith DE. In vivo absorption and disposition of cefadroxil after escalating oral doses in wild-type and PepT1 knockout mice. Pharmacol Res. 2013;30:2931-9.

44. Epling D, Hu Y, Smith DE. Evaluating the intestinal and oral absorption of the prodrug valacyclovir in wildtype and huPepT1 transgenic mice. Biochem Pharmacol. 2018;155:1-7.

45. Ganapathy ME, Huang W, Wang H, Ganapathy V, Leibach FH. Valacyclovir: a substrate for the intestinal and renal peptide transporters PEPT1 and PEPT2. Biochem Biophys Res Commun. 1998;246:470-5.

46. Braun P, Tillotson JR, Wilcox C, Finland M. Cephalexin and cephaloglycin activity in vitro and absorption and urinary excretion of single oral doses in normal young adults. Appl Microbiol. 1968;16:1684-94.

47. de Miranda P, Krasny HC, Page DA, Elion GB. Species differences in the disposition of acyclovir. Am J Med. 1982;73:31-35.

48. Liao $X Y$, Deng QQ, Han L, Wu ZT, Peng ZL, Xie Y, et al. Leflunomide increased the renal exposure of acyclovir by inhibiting OAT1/3 and MRP2. Acta Pharmacol Sin. 2020;41:129-37. 
49. Tramonti G, Xie P, Wallner El, Danesh FR, Kanwar YS. Expression and functional characteristics of tubular transporters: P-glycoprotein, PEPT1, and PEPT2 in renal mass reduction and diabetes. Am J Physiol Ren Physiol. 2006;291:F972-80.

50. Nowicki MT, Aleksunes LM, Sawant SP, Dnyanmote AV, Mehendale HM, Manautou JE. Renal and hepatic transporter expression in type 2 diabetic rats. Drug Metab Lett. 2008;2:11-7.

51. Phatchawan A, Chutima S, Varanuj C, Anusorn L. Decreased renal organic anion transporter 3 expression in type 1 diabetic rats. Am J Med Sci. 2014;347:221-7.

52. Sharma K, Karl B, Mathew AV, Gangoiti JA, Wassel CL, Saito R, et al. Metabolomics reveals signature of mitochondrial dysfunction in diabetic kidney disease. J Am Soc Nephrol. 2013;24:1901-12.

53. Singer-Englar T, Barlow G, Mathur R. Obesity, diabetes, and the gut microbiome: an updated review. Expert Rev Gastroenterol Hepatol. 2019;13:3-15.

54. Maeda T, Miyata M, Yotsumoto T, Kobayashi D, Nozawa T, Toyama K, et al. Regulation of drug transporters by the farnesoid $\mathrm{X}$ receptor in mice. Mol Pharmacol. 2004;1:281-9.

55. Kim I, Ahn SH, Inagaki T, Choi M, Ito S, Guo GL, et al. Differential regulation of bile acid homeostasis by the farnesoid $\mathrm{X}$ receptor in liver and intestine. $J$ Lipid Res. 2007;48:2664-72.
56. Wang $X$, Wang $F$, Zhang $Y$, Xiong $H$, Zhang $Y$, Zhuang $P$, et al. Diabetic cognitive dysfunction is associated with increased bile acids in liver and activation of bile acid signaling in intestine. Toxicol Lett. 2018;287:10-22.

57. Okamura A, Koyanagi S, Dilxiat A, Kusunose N, Chen JJ, Matsunaga N, et al. Bile acid-regulated peroxisome proliferator-activated receptor-alpha (PPARalpha) activity underlies circadian expression of intestinal peptide absorption transporter PepT1/SIc15a1. J Biol Chem. 2014;289:25296-305.

58. Shimakura J, Terada $T$, Saito $H$, Katsura $T$, Inui K. Induction of intestinal peptide transporter 1 expression during fasting is mediated via peroxisome proliferatoractivated receptor alpha. Am J Physiol Gastrointest Liver Physiol. 2006;291:G851-6.

59. Saito H, Terada T, Shimakura J, Katsura T, Inui K. Regulatory mechanism governing the diurnal rhythm of intestinal $\mathrm{H}^{+}$/peptide cotransporter 1 (PEPT1). Am J Physiol Gastrointest Liver Physiol. 2008;295:G395-402.

60. Hirai T, Fukui Y, Motojima K. PPARalpha agonists positively and negatively regulate the expression of several nutrient/drug transporters in mouse small intestine. Biol Pharm Bull. 2007;30:2185-90.

61. Adithan C, Sriram G, Swaminathan RP, Shashindran CH, Bapna JS, Krishnan M et al. Differential effect of type I and type II diabetes mellitus on serum ampicillin levels. Int J Clin Pharmacol Ther Toxicol. 1989;27:493-8. 